Ricardo Fabrino Mendonça*

\title{
Democracia e desigualdade:
} as contribuições da teoria do reconhecimento

A teoria do reconhecimento não é uma teoria democrática na acepção mais usual do conceito. ${ }^{1}$ Pelo menos, não foi proposta como tal. Trata-se de uma teoria da justiça que ganhou diferentes contornos em autores distintos. No entanto, em todos eles, o foco é pensar as condições de superação de formas de opressão social que sistematicamente subordinam alguns indivíduos e grupos a outros. A teoria parte, pois, da constatação da desigualdade para conceber rotas profícuas em direção à emancipação e a um mundo mais igualitário.

Esse foco na promoção da igualdade, bem como os meios propostos para sua realização, torna interessante a reflexão sobre a interface entre reconhecimento e democracia. Há uma teoria democrática a atravessar a teoria do reconhecimento? O que a teoria do reconhecimento tem a dizer para a teoria democrática? Que contribuições conceituais emergem desse diálogo?

Essas são algumas das questões que conduzem o presente artigo. $\mathrm{O}$ objetivo é evidenciar que a teoria do reconhecimento resgata e renova os ideais democráticos de John Dewey, dando-lhes nova envergadura crítica e abrindo ricas portas para se pensar a noção de democracia em contextos marcados

\footnotetext{
É professor do Departamento de Ciência Política da Universidade Federal de Minas Gerais (Belo Horizonte, MG, Brasil). E-mail: ricardofabrino@fafich.ufmg.br.

Texto apresentado no Simpósio Nacional sobre Democracia e Desigualdades, organizado pelo Grupo de Pesquisa sobre Democracia e Desigualdades da Universidade de Brasília (Demodê). O artigo faz parte de um projeto de pesquisa intitulado A apropriação do pragmatismo pela teoria crítica, que recebe apoio da PRPq (Universidade Federal de Minas Gerais) e do CNPq (Processo: 476130/2011-5). A essas instâncias, sou grato pelo financiamento.
} 
por profundas desigualdades. Desse frutífero diálogo, nasce uma abordagem democrática da justiça que tem, pelo menos, cinco pontos fortes: (1) adota uma concepção não institucional de política; (2) parte da constatação da opressão; (3) ultrapassa a dualidade entre público e privado; (4) opera com uma visão não homogeneizadora de igualdade; e (5) quebra a cristalizada dicotomia entre indivíduo e comunidade, que alimenta a suposta oposição entre liberalismo e comunitarismo.

$\mathrm{O}$ artigo está estruturado em duas grandes partes. $\mathrm{Na}$ primeira delas, apresenta-se, brevemente, a teoria do reconhecimento tal como advogada por Axel Honneth, e se traçam as bases deweyianas dessa abordagem. Para tanto, será necessário desenvolver com mais vagar algumas das principais ideias de Dewey, de modo a apontar as consequências delas sobre a teoria de Honneth. A segunda parte desenvolve cada um dos cinco pontos mencionados no parágrafo anterior. Por meio deles, procura-se ressaltar a proficuidade do diálogo entre reconhecimento e democracia.

\section{Reconhecimento, autorrealização e democracia: de Honneth a Dewey}

É preciso afirmar, antes de tudo, que não há uma teoria do reconhecimento. Existem várias delas, desde que o conceito ganhou os holofotes da filosofia política. Entre as abordagens de Taylor, Honneth, Fraser, Markell, Galeotti, McNay e Tully notam-se diferenças profundas, que envolvem desde premissas conceituais até as soluções prescritas. Neste artigo, não é meu intuito mapear tais abordagens e suas diferenças, tarefa a que já me dediquei em outro trabalho (Mendonça e Ayirtman, 2007). Também não poderei advogar algumas das vantagens da proposta de Honneth ou rebater certas críticas a ela que considero problemáticas (cf. Mendonça, 2009, 2011a). Tampouco explorarei os efetivos limites que percebo na abordagem (cf. Mendonça, 2011b). Para avançar o argumento base do presente artigo, parto da teoria de Honneth, a fim de explorar suas contribuições para pensar o tema democracia e desigualdade.

A teoria do reconhecimento de Axel Honneth é um projeto filosófico para a renovação da teoria crítica. Trata-se, pois, por um lado, de uma abordagem que dá continuidade aos ideais expressos por Horkheimer na década de 1930, segundo os quais teorias sociais não podem se limitar a descrever a realidade existente, mas deveriam refletir sobre as condições para a construção de um 
mundo menos opressivo. Por outro lado, a abordagem do reconhecimento promove rupturas tanto na matriz marxista da primeira geração de Frankfurt como na virada argumentativa promovida por Habermas. Honneth pavimenta novas vias para um diagnóstico crítico da atualidade, que permite pensar caminhos originais para a emancipação.

De forma bastante sintética, Honneth (2003a) articula o idealismo hegeliano ao pragmatismo de G. H. Mead para propor uma teoria da justiça centrada no conceito de autorrealização. Para Honneth (2001a, 2003a, 2003b, 2003c), as lutas por reconhecimento impulsionam a ação dos sujeitos no mundo e o progresso moral da sociedade, sendo que o parâmetro de tais lutas é o anseio pela autorrealização. Segundo ele, as configurações atuais das sociedades ocidentais levaram à consolidação de três domínios essenciais à autorrealização: o afeto, os direitos e a estima social. A possibilidade de experienciar vínculos afetivos fortes, de ver-se semelhante aos outros no exercício de direitos e deveres e de ser apreciado por eventuais contribuições à consecução de objetivos coletivos permite ao sujeito realizar-se em múltiplas dimensões. Do afeto, dos direitos e da possibilidade de ser estimado adviriam, respectivamente, a autoconfiança, o autorrespeito e a autoestima (Honneth, 2003a).

A Honneth (2003a) interessa, sobretudo, a dimensão política e motivacional dessa batalha por autorrealização - autorrealização, vale lembrar, que não significa uma luta por autoconservação individual, como em Hobbes e Maquiavel (Honneth, 2003a). Também não se trata de uma espécie de busca pelo bem-estar individual ou da reles autoafirmação (Mendonça, 2009). A autorrealização em Honneth é um princípio normativo que revela um telos dinâmico e contextual. Trata-se de uma construção intersubjetiva, histórica e dialógica (Tully, 2000, 2004). De acordo com o filósofo alemão, o esforço perene por autorrealização alimenta processos interacionais em que atores sociais lutam para serem reconhecidos como pessoas, como seres humanos e como indivíduos.

Essas lutas nascem da percepção de que determinadas situações e práticas sociais são desrespeitosas. Quando os sujeitos percebem que as condições de autorrealização, em alguma de suas dimensões, são-lhes cerceadas pelos atos de outros seres humanos, tendem a sentir-se indignados e esse sentimento pode desencadear ações políticas. Isso não significa que o desrespeito conduza necessariamente à indignação e à luta. Honneth é bastante claro ao argumentar que tal passagem depende de uma série de variáveis contextuais, não ocorrendo de maneira mecânica ou natural. Para que a luta ocorra também se faz 
fundamental “socializá-la”, evidenciando que a situação problematizada não é puramente individual, mas diz respeito à coletividade.

Nesse viés, a opressão contém os germes da luta, que, segundo Honneth, seria guiada pelo princípio normativo da autorrealização, fundamento de sua concepção formal de eticidade. Esta "tem de conter todos os pressupostos intersubjetivos que hoje precisam estar preenchidos para que os sujeitos se possam saber protegidos nas condições de sua auto-realização" (Honneth, 2003a, p. 270). Serve de parâmetro para balizar a justiça de certas reivindicações sua capacidade de inclusão tanto de pessoas como de dimensões da autorrealização, sendo que o critério da reciprocidade tem aí papel fundamental (Forst, 2007; Mendonça, 2009).

A teoria do reconhecimento oferece uma abordagem para se pensar a ideia de justiça e de superação de práticas opressivas. Mas qual a sua relação com a democracia? Que contribuições o conceito de reconhecimento pode trazer à teoria democrática? Há uma teoria democrática subjacente à proposta de Honneth? Ou ainda, e mais ousadamente, pode-se pensar a teoria do reconhecimento como uma teoria democrática?

Para refletir sobre essas questões, é importante recuperar, aqui, a ligação, frequentemente negligenciada, da teoria do reconhecimento com o pragmatismo de John Dewey. As ideias do filósofo norte-americano permitem reenquadrar o próprio sentido da democracia e ajudam a revelar facetas interessantes da proposta de Honneth. Se, em uma acepção tradicional de teoria democrática, a teoria do reconhecimento não preenche quesitos elementares (como o delineamento institucional do funcionamento do sistema político), o resgate da ideia de democracia faz vislumbrar outros rumos para a teoria democrática - rumos estes que podem ver-se enriquecidos pela teoria do reconhecimento.

\section{Dewey e a ideia de democracia}

É fundamental compreender a influência das ideias de Dewey sobre Honneth caso se deseje entender a teoria do reconhecimento e sua base democrática. O filósofo alemão reconhece explicitamente essa influência no tocante a dois aspectos centrais de sua teoria. O primeiro deles é o conceito de ação, que se vincula fortemente às emoções e aos sentimentos dos sujeitos (Honneth, 2003a). O segundo é a noção de cooperação social e a importância do trabalho para ela, o que lhe permite pensar a dimensão simultaneamente 
coletiva e individual dos processos políticos, bem como a natureza moral da distribuição de recursos materiais (Honneth, 2001b). É possível traçar, todavia, várias outras articulações entre Dewey e Honneth, o que demanda a discussão de algumas das ideias do pragmatista norte-americano.

John Dewey é um autor extremamente influente no campo da educação e da psicologia. Na teoria política, sua obra tem ganhado crescente atenção depois que Richard Rorty o colocou como um dos três maiores filósofos do século XX, ao lado de Heidegger e de Wittgenstein (Joas, 1993). Sua vasta obra encampa temas que vão da estética ao funcionamento psíquico, passando pela pedagogia, pela antropologia e pelas instituições políticas. Tal vastidão não implica, contudo, um ecletismo fragmentado. Sua obra é atravessada pela defesa radical da democracia em um período conturbado da história contemporânea. A Revolução Russa, a ascensão do nazifascismo, a crise de 1929, o New Deal e as duas grandes guerras atravessam os escritos do autor, que se viu preocupado com a construção de uma sociedade mais justa (em seus meios e fins).

É, portanto, equivocado tratar o pragmatismo como uma tradição filosófica ingênua e despolitizada, cujo foco nas microinterações implicaria a perda do contexto mais amplo. O pragmatismo filosófico de Dewey (e de Mead, deve-se dizer) sempre foi profundamente político (a esse respeito ver Hildreth, 2009; Pogrebinschi, 2004, e Joas, 1993). Dewey foi um crítico voraz de seu tempo, atacando as desigualdades econômicas, a intolerância racial, a opressão de gênero e, de maneira geral, o enfraquecimento do público alimentado pelo economicismo tanto do capitalismo vigente como do socialismo real (sobre essas críticas, ver Dewey, 1954, 1964, 1970). Suas preocupações alimentaram um esforço permanente pela construção de uma sociedade que: assegurasse a liberdade aos indivíduos, sem atomizá-los; fomentasse fins igualitários, sem o uso de meios violentos; e permitisse a autorrealização dos sujeitos, sem promover o anseio pela autoafirmação.

Para entender, de forma sintética, a estrutura de sua posição política é preciso partir de uma de suas distinções mais célebres: a diferença entre democracia como ideia e democracia como sistema de governo (Dewey, 1954 [1927]). A primeira consiste nos ideais de democracia, em seus pilares morais e conceituais que apregoam uma forma de governo calcada na igualdade, na participação e na decisão coletiva sobre os rumos da sociedade. A segunda, por sua vez, revela-se na institucionalização de uma forma de governo, com seus procedimentos, práticas e padrões de funcionamento. 
Para Dewey (1954), embora boa parte da teoria democrática se concentrasse sobre a segunda, seria preciso retomar a primeira para que a radicalidade do projeto democrático pudesse se realizar (Dewey, 1970 [1939]). Não basta compreender o funcionamento do sistema político e aperfeiçoar suas instituições. É preciso ter muito claros os fins da democracia para que se pensem meios adequados de realizá-los. Para Dewey, tais meios não estariam prontos em instituições como o sufrágio, as eleições periódicas e a regra da maioria. A democracia é, de acordo com ele, um projeto que se refaz o tempo todo, e sua radicalidade reside nessa natureza dinâmica. "Uma vez que as condições da ação [...] e do conhecimento estão sempre mudando, o experimento precisa sempre ser re-tentado; o Estado deve sempre ser redescoberto" (Dewey, 1954, p. 34).

Sua aposta é nos sujeitos como atores da história, capazes de estruturar a vida comunal de modo a possibilitar a autorrealização coletiva:

a democracia sempre esteve unida ao humanismo e à sua fé nas potencialidades da natureza humana e sua necessidade presente é uma vigorosa reafirmação dessa fé, que desenvolveu importantes ideias e se manifestou em atitudes práticas (Dewey, 1970 [1939], p. 212).

Ainda de acordo com Dewey, "a democracia se expressa nas atitudes dos seres humanos e se mede pelas consequências produzidas em suas vidas" (Dewey, 1970 [1939], p. 213). O projeto democrático consolida-se no esforço coletivo por entender as consequências comuns de interações sociais e por fazer escolhas políticas para lidar com elas. Para compreender essa questão, faz-se necessário retomar, aqui, dois conceitos do autor que embasam sua visão radical de democracia: o de experiência e o de público.

A noção de experiência atravessa a obra de Dewey e ganha contornos bastante claros em Arte como experiência, livro originado de uma série de conferências, em 1931, sobre filosofia da arte. Sem enveredar pelos meandros da rica discussão estética de Dewey, interessa notar que a experiência é um processo que brota da transação de um ser com o ambiente. A experiência é um misto de padecer e agir, em que ambiente e ser modificam-se mutuamente e se tornam. Nas palavras de Dewey:

A experiência é uma questão de interação do organismo com seu meio, um meio que é tanto humano quanto físico, que inclui o material da tradição e das instituições, 
bem como das circunvizinhanças locais [...]. O eu tanto age quanto é submetido ao que vem de fora, e aquilo a que fica sujeito não são impressões estampadas em uma cera inerte, mas depende do modo como o organismo reage e responde. Não há experiência em que a contribuição humana não constitua um fator determinante do que de fato acontece. [...] Em uma experiência, coisas e eventos que fazem parte do mundo físico e social são transformadas pelo contexto humano em que entram, enquanto a criatura viva se modifica e se desenvolve através da interação com coisas que antes lhe eram externas (2010, p. 430-1).

O desdobramento de uma experiência envolve, portanto, um processo de adaptação mútua entre sujeito e meio. Essa ideia ajuda a compreender a concepção não atomística de indivíduo advogada por Dewey. O indivíduo é fruto de associações constitutivas, já que a interdependência é inerente às transações. "Associação, no sentido de conexão e combinação, é uma 'lei' de tudo o que se conhece como existente. Coisas singulares agem, mas elas agem juntas" (Dewey, 1954, p. 22). Como lembra Dewey em "Liberalismo \& ação social", "as reais 'leis' da natureza humana são leis dos indivíduos em associação e não de seres na condição mítica de separados” (1970 [1935], p. 48).

Se a associação é parte constitutiva dos indivíduos, a questão passa a ser, para Dewey, entender as formas que essa associação pode assumir. E é, justamente, aqui que o conceito de público se articula ao de experiência para clarear sua compreensão da democracia. De acordo com Dewey (1954), os atos humanos têm consequências sobre outras pessoas, podendo tanto afetar apenas aqueles diretamente engajados em uma interação como se estender e incidir, indiretamente, sobre outras pessoas. "O público consiste de todos aqueles que são afetados pelas consequências indiretas de transações na medida em que se considera necessário cuidar sistematicamente dessas consequências" (Dewey, 1954, p. 16). O público nasce do reconhecimento dos efeitos partilhados de algumas ações e do interesse comum em encontrar meios de lidar com eles. Trata-se de uma agência coletiva, que se propõe a refletir e a agir a partir de uma experiência, participando do delineamento do curso dos acontecimentos.

A conformação e a atuação de um público dão-se, para Dewey, por meio da comunicação. O medium da linguagem, com seu enraizamento cultural, permite que os indivíduos se articulem em uma associação consciente de seu destino comum. 
Comunicar é o processo de criar uma participação, de tornar comum o que era isolado e singular [...]. Os homens [sic] se associam de muitas maneiras. Mas a única forma de associação que é verdadeiramente humana, e não uma reunião gregária em busca de calor e proteção, ou um mero recurso para chegar à eficiência na ação externa, é a participação nos significados e nos bens efetuada pela comunicação (Dewey, 2010, p. 427-428).

Na ótica de Dewey, a comunicação é a base para a formação da comunidade, o que é vital para a vida política. Por comunidade, Dewey não entende um agrupamento reduzido de pessoas que se conhecem e interagem ordinariamente. Isso fica claro quando se recorda sua defesa da necessidade de uma Grande Comunidade, capaz de alterar práticas e instituições geradas pelos processos de industrialização e urbanização que produziram a Grande Sociedade. O conceito de comunidade envolve a criação de um sentido comunal, que poderia ultrapassar os limites da escala local, desde que o interesse público e a livre comunicação guiassem um processo de busca coletiva de soluções para problemas sociais.

Aqui chegamos a outro elemento do conceito de público a ser destacado: sua ligação com problemas sociais. Públicos emergem em torno de problemas que geram interrupções no curso normal das ações e permitem colocar em suspenso formas naturalizadas de comportamento. Problemas despertam emoções, convocam ações e podem impulsionar respostas coletivas, na medida em que demandam que se testem hipóteses sobre o futuro.

Esse teste de hipóteses deve seguir os rigores de uma pesquisa científica, incorporando todas as visões relevantes e abrindo-se ao escrutínio comunicativo. "Somente a investigação contínua, no sentido de articulada e persistente, pode prover o material da opinião estável sobre assuntos públicos" (Dewey, 1954, p. 178). É preciso que a pluralidade de perspectivas se apresente, para que se construa um caminho comum e refletido sobre a maneira de superar determinado problema. Tal como na ciência, essa pesquisa social envolve uma forma de cooperação comunicativa entre os membros da comunidade, o que não exclui a competição. Como explica Pogrebinschi (2004, p. 51):

A solução para tais conflitos é a "cooperação amigável" - que, como nos esportes, pode incluir a rivalidade e a competição, porém não a força - que se exerce, no âmbito do debate e da inteligência, por meio da tentativa constante de aprender-se alguma coisa com aqueles de quem discordamos. 
Democrático para Dewey é esse processo por meio do qual públicos se debruçam sobre problemas coletivos e os resolvem de modo coletivo. Justamente por isso, a democracia não se resume ao funcionamento institucional do sistema político. "A ideia de democracia é uma ideia mais ampla e completa do que pode ser exemplificado pelo Estado, mesmo em sua melhor forma. Para ser realizada, ela deve afetar todos os modos de associação humana, a família, a escola, indústria, religião" (Dewey, 1954, p. 143). A democracia é a ideia da vida comunal em sua dimensão moral.

O problema da democracia faz-se o problema de uma forma de organização social, estendida a todas as áreas e modos de vida, em que as potencialidades dos indivíduos não somente estejam livres de constrangimento mecânico externo mas sejam estimuladas, sustentadas e dirigidas (Dewey, 1970 [1935], p. 39).

A democracia é um programa exigente que deve ser sustentado. Para que essa vida comunal seja viável e para que a realização seja possível, desigualdades precisam ser frontalmente atacadas. Vale lembrar que essas desigualdades envolvem diferenças econômicas, na medida em que estas constrangem, sistematicamente, a liberdade de indivíduos, a inserção deles na comunidade e sua participação nos processos coletivos de resolução de problemas sociais. Para Dewey (1970 [1939], p. 157), "as desigualdades econômicas produzidas reagiram contra a existência de igualdade de oportunidade".

É interessante notar, contudo, que Dewey não opõe o princípio da igualdade ao de singularidade. Ao contrário, a igualdade é fundamental para que os indivíduos se realizem em sua unicidade.

Igualdade não significa o tipo de equivalência matemática ou física em virtude da qual qualquer elemento pode ser substituído por outro. Ela denota consideração efetiva por qualquer coisa que seja distintiva ou única em cada um, independentemente de desigualdades físicas e psicológicas. Não se trata de uma possessão natural, mas é um fruto da comunidade quando sua ação é dirigida pelo seu caráter como comunidade (Dewey, 1954, p. 151).

Para Dewey, a democracia é a forma da comunidade que permite essa igualdade atenta ao singular e, simultaneamente, o meio para alcançá-la. Isso porque o pragmatista americano destaca a indissociabilidade de fins 
e meios. Aí reside uma de suas críticas à maioria dos marxistas² : se os fins buscados são os da liberdade e da igualdade, não seria profícuo prever que violência e ditadura pudessem conduzir a eles. As lutas por justiça deveriam basear-se na liberdade e na igualdade, empregando métodos democráticos para a realização de fins democráticos.

Essa breve apresentação da ideia de democracia tal como advogada por Dewey ajuda a compreender as profundas ligações da obra de Honneth com o pragmatista norte-americano e sua relevância democrática. A próxima seção chama a atenção para algumas dessas ligações, possibilitando a passagem para a segunda parte do artigo, na qual se discutem contribuições da teoria do reconhecimento à teoria democrática.

\section{De Dewey a Honneth: a autorrealização democrática}

A teoria do reconhecimento de Honneth propõe um quadro conceitual que pensa o papel das lutas por autorrealização no progresso moral da sociedade. Como já discutido, a abordagem costura premissas psicológicas à compreensão de macroprocessos sociopolíticos. Esse movimento é bastante semelhante ao de Dewey, que parte de discussões sobre a natureza, o caráter e as motivações da ação dos sujeitos para realizar uma crítica de seu tempo e propor uma ampla abordagem política.

A articulação entre Honneth e Dewey não se restringe, contudo, à estrutura formal da argumentação. A substância da conexão entre o psicológico e o sociopolítico que realizam é muito similar, a começar pelos fins idealizados por ambos. Tanto a Honneth como a Dewey interessa uma ordem social que permita a "liberação dos indivíduos de modo que a realização de suas capacidades seja a lei de suas vidas" (Dewey, 1970 [1935], p. 60). É preciso assegurar condições para o florescimento humano, o que demanda a existência de uma igualdade que se combina com a possibilidade de valorização da singularidade. Novamente nos termos de Dewey (1964, p. 99): "As condições sociais devem ser tais que todos os indivíduos possam exercer sua própria iniciativa num meio social, desenvolvendo suas capacidades pessoais e recompensando seus esforços" (1964, p. 99).

\footnotetext{
Em"Liberdade e cultura"(1939), Dewey também critica o determinismo econômico e a subvalorização de outras dimensões dos processos políticos. Ele lembra, por exemplo, que a"formação de uma classe, especialmente a consciência de classe, depende da operação de fatores psicológicos, os quais não são mencionados - e que a teoria rejeita" (Dewey, 1970 [1939], p. 189).
} 
Esse fim não implica a adoção de um telos fixo, previamente estabelecido. A autorrealização prescrita por Honneth (2003a, 2003b, 2003c) é uma construção histórica, podendo assumir formatos diferentes em contextos distintos. Do mesmo modo, Dewey (1964, p. 98) deixa claro que a definição de justiça só pode ser feita situacionalmente, na medida em que se observam as consequências que promovem o bem-estar humano. Dewey defende uma moralidade reflexiva não baseada em leis gerais.

Cabe salientar, ainda, que a preocupação com a realização das capacidades individuais não implica, em nenhum dos autores, a defesa do individualismo metodológico. Dewey é um crítico atroz da visão atomista, e Honneth recorre a Hegel e Mead para edificar toda uma abordagem alicerçada em premissas intersubjetivas. Justamente por isso, nem Honneth nem Dewey defendem formas de autoafirmação. Honneth pressupõe que reivindicações de autorrealização só são justas na medida em que propõem gramáticas válidas também para outros sujeitos. ${ }^{3}$ Dewey defende a mesma ideia quando afirma que o mal reside em contradizer "não uma lei abstrata da razão mas o princípio da reciprocidade, quando se recusa a estender a outros os bens que procura para si” (1964, p. 77).

Outro forte vínculo entre as ideias de Honneth e as de Dewey reside na percepção do conflito como elemento que propele mudanças sociais. Ambos partem do pressuposto de que problemas vivenciados concretamente por sujeitos no mundo podem desencadear formas de ação organizadas, cujos objetivos envolvem a transformação das gramáticas morais vigentes. Em Honneth (2003a), a luta contra o desrespeito é o motor de processos transformativos, capazes de fomentar um mundo mais justo em que a autorrealização seja mais complexa e inclusiva. Para Dewey (1970 [1939], p. 217), a supressão da possibilidade de realização nutre revoltas, que podem despertar públicos. A luta destes abre novos horizontes morais, contestando hábitos enraizados (Dewey, 1964, p. xiii).

Os dois filósofos também se alinham ao perceber a centralidade das identidades nessas lutas morais. Dewey explicita esse ponto ao admitir que a “verdadeira questão moral está em saber qual a espécie de 'eu' que está sendo promovida e formada" (1964, p. 143). Honneth constrói toda sua abordagem a partir da ideia de que é o processo interativo de construção de identidades que elucida as lutas por reconhecimento e impulsiona os conflitos sociais.

\footnotetext{
Para o desenvolvimento desse argumento, ver Mendonça (2009).
} 
O meio pelo qual tais conflitos se desdobram também aproxima Honneth e Dewey. Ainda que Dewey dê um peso maior que Honneth ao debate público, ambos frisam a natureza democrática dos conflitos sociais, os quais possibilitam o surgimento de sociedades (e não apenas de Estados) mais propícias à autorrealização. Justiça e democracia se alimentam mutuamente, sendo que uma não pode existir sem a outra. A luta por justiça gera democracia ao mesmo tempo em que depende dela.

Nesse processo, um último ponto de aproximação entre os autores merece menção. As lutas por justiça, de que depende o vigor democrático, não são conflitos racionais, pautados apenas por interesses. Trata-se de lutas profundas, apaixonadas, que tocam no âmago dos sujeitos e de suas identidades. Isso ajuda a entender o cuidado de ambos os autores em discutir o papel político das emoções. Dewey ressalta a dimensão motivacional das emoções e é taxativo ao afirmar que "emoções e imaginação são mais potentes em moldar o sentimento e a opinião pública de que a informação e a razão" (Dewey, 1970 [1939] p. 103). Honneth, baseando-se em Dewey, também ressalta a impulsão emotiva dos atos sociais, além de situar o amor como um dos domínios da autorrealização.

As aproximações aqui apresentadas, embora excessivamente ligeiras e sintéticas, ajudarão a entender a proficuidade do diálogo entre reconhecimento e democracia - proficuidade esta que, a meu ver, reside na configuração de uma proposta teórica que não apenas atenta para as desigualdades estruturais existentes nas democracias contemporâneas mas as coloca no centro da própria teoria. Este argumento será desenvolvido ao longo da segunda parte do presente artigo, atravessando suas subseções.

\section{Reconhecimento como teoria democrática?}

Como expresso na primeira frase do presente artigo, em uma concepção tradicional, não se pode dizer que a abordagem do reconhecimento seja uma teoria democrática. Ao se expandir o conceito de democracia para explorar seus pilares, contudo, é possível pensar a teoria do reconhecimento como uma abordagem profundamente marcada por uma teoria democrática. A base do ideário democrático é a ideia de uma comunidade política que se autogoverna, o que requer alguma forma de igualdade entre os membros dessa comunidade e algum tipo de participação desses membros, de modo que o autogoverno se materialize em práticas concretas (esporádicas ou continuadas). 
A teoria do reconhecimento de Honneth oferece esses elementos, desde que o autogoverno não seja restringido à elaboração legislativa no interior do Estado. $\mathrm{Na}$ trilha do legado deweyano, a teoria do reconhecimento expande a ideia de autogoverno, de modo a encampar a construção das gramáticas morais que regem a sociedade. Seu foco de preocupação não se volta à confecção ordinária de leis, mas à estruturação das condições sociais que permitem que os membros de uma coletividade efetivamente decidam seus rumos.

Pensando a teoria do reconhecimento como uma teoria expandida de democracia, gostaria de argumentar que ela possui cinco pontos fortes para a reflexão sobre desigualdades, os quais foram mencionados na introdução deste artigo e serão desenvolvidos adiante. Embora nenhum desses pontos seja exclusividade da teoria do reconhecimento, a conjunção entre eles permite vislumbrar uma abordagem muito interessante para se pensar a ideia de democracia em um mundo desigual.

\section{Política para além do sistema político}

O primeiro ponto a ser destacado sobre a teoria do reconhecimento é sua concepção não institucional de política. Como uma parcela significativa das teorias democráticas contemporâneas, essa abordagem não resume a política aos jogos de poder que ocorrem nos meandros do sistema político. A política não se limita a instituições formais, às eleições, à luta por cadeiras do Legislativo, às competições partidárias, às coalizões de governo ou às políticas públicas implementadas pelo Estado.

Na teoria do reconhecimento, a concepção original de política é retomada, encampando tudo o que diz respeito à coletividade. E o que diz respeito à coletividade, nessa abordagem, é aquilo que permeia os processos identitários, fortalecendo ou cerceando as condições de autorrealização. Na medida em que as identidades são percebidas como políticas, as interações cotidianas de diversas naturezas passam a merecer atenção, visto ajudarem a compreender as opressões e lutas que atravessam processos sociais.

É importante salientar que a formação das identidades é política não apenas no sentido de que há identidades coletivas que apresentam demandas públicas. Na visão de Honneth, a base interacional da construção dos selves é política, visto ser atravessada por relações de poder de diversas ordens. $\mathrm{O}$ self se constrói intersubjetivamente, e tal processo abre possibilidades para 
lutas permanentes. Quando sujeitos veem negadas suas expectativas morais, podem lutar, de diversas maneiras, para deslocar práticas e gramáticas morais de modo a ampliar as condições da autorrealização.

Não faz, pois, sentido afirmar que Honneth opera com uma teoria psicológica de justiça que seria pré-política. O que Honneth faz é trabalhar com o conceito ampliado de política, expandindo não apenas as arenas de seu exercício mas também as dimensões que lhe dizem respeito. A dimensão psicológica só pode ser pré-política caso se opere com uma visão que concebe os sujeitos como entidades prontas a se encontrarem na cena pública. Do contrário, a própria formação do self e as relações que a atravessam passam a merecer atenção.

É nessa segunda possibilidade que Honneth aposta, o que explica a construção de uma teoria da justiça em que não apenas os direitos mas o amor e a estima social ganham relevo. A politização da formação do self também elucida a atenção a espaços fundamentais da vida social, como o trabalho e as relações domésticas. Na teoria do reconhecimento, a política é difusa e capilarizada, evidenciando a complexidade das relações de opressão e das lutas para contestá-las.

A concepção de política com que trabalha a teoria do reconhecimento é adequada à construção de uma teoria democrática frontalmente preocupada com as desigualdades sociais em seus diversos matizes. Ao operar com a ideia de democracia, no sentido deweyano do termo, Honneth mantém acesa a dimensão normativa da teoria democrática e busca pensar processos que possibilitem a produção coletiva de uma sociedade mais justa. A política ampliada convida à construção de uma democracia espraiada, que se manifesta como uma forma de vida.

Não basta, assim, democratizar o sistema político. Como já apontava Dewey (1954), mais da mesma democracia pode até ser antidemocrático. É preciso democratizar as relações sociais, transformando a democracia em uma forma de vida que embasa e fortalece a existência comunal. É preciso perceber as várias desigualdades incrustadas no cotidiano que limitam a liberdade dos sujeitos e a possibilidade de autorrealização. É preciso combater as práticas sociais que inviabilizam que certos sujeitos participem da configuração coletiva da sociedade em que vivem. É preciso expandir a ideia de autogoverno para que ele tenha algum sentido prático. 


\section{A centralidade da constatação da opressão}

Se a igualdade é uma dimensão fundamental da ideia de democracia, desigualdades diversas não podem ser tratadas como aspectos secundários da vida política. Desigualdades não são falhas ocasionais da vida em comunidade a serem tratadas pontualmente. Elas tampouco devem ser camufladas em nome de uma igualdade política formalmente assegurada. Desigualdades precisam ser colocadas no cerne da teoria democrática, na medida em que cerceiam a possibilidade do autogoverno e o florescimento das capacidades humanas.

A teoria do reconhecimento assume esse pressuposto, lidando, de maneira frontal e integral, com as desigualdades. Na linguagem de Honneth, as desigualdades são tratadas como formas de desrespeito, que alimentam e motivam as lutas políticas. Ao revelar a injustiça das desigualdades, tais lutas permitem o desenvolvimento de novas gramáticas morais, fomentando não apenas a realização dos sujeitos mas também a construção de sociedades mais justas. A atenção às desigualdades acompanha, portanto, toda a cadeia do processo agonístico delineado por Honneth. Elas são o gatilho do processo, o meio de seu desdobramento e o problema contra o qual se luta.

Uma leitura apressada do trabalho de Honneth poderia situar a discussão das desigualdades apenas no segundo domínio da autorrealização tratado pelo autor. De fato, o filósofo alemão diagnostica a consolidação moderna de uma dimensão universalizante da justiça que propaga o ideal da igualdade. Essa dimensão, expressa na ideia de direitos, possibilitaria aos indivíduos verem-se como dignos do mesmo respeito que devem aos outros. Diferentemente, o domínio da estima social teria se consolidado pelo anseio pela valorização de eventuais contribuições singulares dos indivíduos à realização de objetivos sociais. Isso pode fazer supor que o terceiro domínio de Honneth remete ao fortalecimento de desigualdades e hierarquias (Seglow, 2009; McBride, 2009), bem como à pura valorização de identidades (Fraser, 2003a; Markell, 2003). Não é esse, contudo, seu argumento.

Honneth advoga a importância da simetria da estima (Thompson, 2006). Isso quer dizer que as desigualdades não podem conduzir à desvalorização apriorística dos sujeitos (Mendonça, 2011a). É preciso combater as desigualdades que negam a alguns sujeitos a possibilidade de serem estimados. $\mathrm{O}$ questionamento das desigualdades está, portanto, presente. Do mesmo 
modo, a tematização do desrespeito inerente à violência física, que fere a possibilidade da autoconfiança, revela formas de desigualdade que impedem algumas pessoas de disporem livremente sobre seus corpos.

Nota-se, assim, que o conceito de desrespeito trabalhado por Honneth, em suas múltiplas dimensões, lida centralmente com a temática das desigualdades. O desrespeito é opressivo porque cria hierarquias depreciativas. Ele situa os sujeitos diferentemente na vida social, concedendo oportunidades a alguns e negando-as a outros. A opressão estrutural - que, como discute Young (2000), opera de maneira distinta da tirania - cerceia a possibilidade de alguns sujeitos participarem ativamente da decisão dos rumos da coletividade. Se a democracia é um modo de vida moralmente sustentado, as desigualdades que alimentam a opressão precisam ser confrontadas.

Esse ponto ajuda a esclarecer a centralidade que o questionamento das desigualdades econômicas tem na obra de Honneth, a despeito das várias críticas feitas por Nancy Fraser (2000, 2001, 2003a). Nesse ponto, não surpreendentemente, Honneth é tão injustiçado quanto Dewey. Ambos foram acusados de negligenciar a força das injustiças econômicas, embora ambos tenham dedicado esforço considerável para discuti-las. A questão é que Honneth, na trilha de Dewey, percebe a dimensão moral da distribuição de riquezas e suas consequências mais amplas. Por isso, vale retomar, aqui, duas citações de Dewey:

Por trás da apropriação pelos poucos dos recursos materiais da sociedade está a apropriação pelos poucos, em defesa dos próprios fins, dos recursos culturais, dos recursos espirituais que não são o produto dos indivíduos que deles se apropriaram mas do trabalho cooperativo da humanidade (Dewey, 1970 [1935], p. 58).

[F]atores econômicos são parte intrínseca da cultura que determina a forma atual das medidas e regras políticas (Dewey, 1970 [1939], p. 102).

A grande preocupação com as desigualdades econômicas está declarada, mas a economia não é pensada como um fator isolado. As desigualdades econômicas revelam e implicam uma série de desigualdades, gerando a apropriação indevida do trabalho cooperativo e institucionalizando-se em regras políticas. As escalas e hierarquias que possibilitam a distribuição de riquezas revelam valores sociais mais amplos. 
A teoria do reconhecimento opera com a mesma matriz de raciocínio. As desigualdades econômicas são brutais e precisam ser contestadas. Desigualdades econômicas são tão potentes que afetam a construção dos selves, minando a possibilidade de uma autorrelação saudável (Honneth, 2001a, 2003b) e da consolidação de sujeitos autônomos (Anderson \& Honneth, 2005), aspectos fundamentais para a democracia na visão de Honneth (e de Dewey). As patologias do capitalismo exploradas por Hartmann e Honneth (2006) não deixam dúvidas sobre as consequências nefastas das desigualdades econômicas. Smith lembra que:

Desde seus primeiros escritos sobre a estrutura da teoria crítica social no início dos 1980 até seu recente intercâmbio com Nancy Fraser sobre reconhecimento e redistribuição, o problema da construção de uma crítica substantiva ao trabalho no capitalismo tem sido central à empreitada de Honneth (Smith, 2009, p. 46).

Lutas por reconhecimento precisam, pois, contestar desigualdades econômicas. A superação de tais desigualdades é "um passo em um processo de estabelecimento de uma sociedade que realmente não conheça mais relações institucionalizadas de humilhação" (Honneth, 1997, p. 324). A atenção ao fator econômico não implica, contudo, seu isolamento. Em Honneth, a dimensão econômica integra lutas mais amplas em torno das gramáticas morais que regem as interações sociais. São essas gramáticas que balizam os comportamentos dos sujeitos, a distribuição de riquezas e os valores pelos quais se luta.

Essa visão mais abrangente permite à teoria do reconhecimento trabalhar diversas formas de desigualdade de modo integrado. Desigualdades econômicas, de gênero, raciais e religiosas articulam-se de maneiras complexas. A busca coletiva por justiça, de que depende a ideia de democracia, deve lidar com as múltiplas configurações sócio-históricas por meio das quais desigualdades se manifestam.

Ao oferecer uma matriz teórica que parte da discussão do desrespeito e que busca instâncias intramundanas de transcendência (Alexander e Lara, 1996), Honneth oferece uma interessante contribuição à teoria democrática. A sociedade em que os sujeitos são livres e se governam é a sociedade em que podem tematizar publicamente suas desigualdades e lutar contra a opressão e o desrespeito. A teoria do reconhecimento não oferece apenas um fim demo- 
crático expresso na supressão das desigualdades, mas também um meio democrático para se lidar com tais desigualdades. Indissociáveis, o meio e o fim da democracia (e da justiça) se revelam na própria contestação das desigualdades.

\section{Para além da dualidade entre público e privado}

O terceiro ponto forte da teoria do reconhecimento revela-se na superação da dicotomia entre público e privado, que permeia teorias democráticas de diferentes matizes. A clássica distinção foi uma das bases da democracia ateniense e atravessou séculos para se atualizar nas instituições políticas dos séculos XVIII e XIX. Ela parte do pressuposto de que o domínio a ser submetido ao controle coletivo é o da vida pública, fazendo-se importante separá-lo, com precisão, do reino privado. Tal delimitação teria basicamente dois propósitos. O primeiro seria impedir que interesses privados se impusessem à coletividade como se fossem interesses comuns. O segundo seria proteger a esfera privada do escrutínio e regramento públicos. Privado e público se complementariam de modo a garantir um sistema democrático saudável.

Se tais ideias podem ser percebidas em autores muito distintos, atribui-se a Hannah Arendt uma de suas formulações mais contundentes. A filósofa alemã ressalta a dimensão pública da política e a necessidade de uma clivagem muito clara entre o público e o privado (Arendt, 2005). Para que o autogoverno fosse possível e o interesse público vigorasse na polis, os interesses parciais e as questões não públicas deveriam permanecer no âmbito privado. Este, por sua vez, é fundamental para que cidadãos livres e reflexivos se formem de modo a trazerem suas singularidades ao espaço público. Para Arendt, um dos problemas da sociedade de massas seria a ascensão do social, que teria embaralhado os espaços outrora distintos do público e do privado. Ao fazê-lo, teria enfraquecido a ambos e minado as bases da democracia.

Coube ao feminismo lançar algumas das primeiras críticas à rigidez da distinção entre público e privado. O argumento de que o pessoal é político expôs várias das práticas opressivas sustentadas por essa dicotomia. A politização dos espaços domésticos e de suas relações evidenciou a impossibilidade de estabelecimento de uma fronteira fixa entre os âmbitos público e privado. Os trabalhos de Carole Pateman (1996) e Susan Okin (1989) são particularmente ricos a esse respeito, salientando como a distinção contribuiu para a formação de práticas e instituições androcêntricas. Como lembra Okin: 
[N]o momento em que reconhecermos que a separação entre o privado e o público é, em grande medida, uma construção ideológica que tem pouca relevância para a vida social humana, poderemos ver, mais claramente, não apenas o potencial, mas também a necessidade de aplicar os critérios da justiça à família (Okin, 1989, p. 24).

Na mesma linha, a teoria do reconhecimento questiona a dicotomização entre público e privado, fazendo-o de diversas maneiras. Em primeiro lugar, como já trabalhado anteriormente, Honneth concebe o político de uma maneira ampla, investigando as formas opressivas e lutas emancipatórias incrustadas no cotidiano. Ao trabalhar com a dimensão política da formação de selves, o autor traz para o cerne das discussões políticas o que há de aparentemente mais privado.

Justamente por isso, as opressões de diversas naturezas se tornam tematizáveis, como explorado acima. A forma como Honneth enfoca as práticas opressivas impede o estabelecimento de um parâmetro fixo de definição do que é de interesse público. Ele vincula as injustiças aos sentimentos dos sujeitos, o que expande o escopo daquilo que pode ser visto como injusto. Isso não implica que Honneth adote um relativismo em que qualquer sentimento de injustiça seria evidência de uma opressão. A baliza da autorrealização e o critério da reciprocidade oferecem parâmetros válidos para esse julgamento (Mendonça, 2009). No entanto, os sentimentos dos oprimidos também são reveladores e podem descortinar modalidades de desrespeito antes não percebidas como tal.

Em segundo lugar, importa ressaltar que Honneth (2003b) critica autores que delimitam os processos políticos ao que se torna publicamente manifesto. Recorrendo a Bourdieu, ele ressalta a invisibilidade de grande parte das injustiças e lutas do mundo. A miséria do mundo existe para além da "articulação política de movimentos sociais” (Honneth, 2003b, p. 117). O que ganha visibilidade na esfera pública descortina apenas um fragmento das formas de desrespeito e das lutas existentes. Honneth (2003b) questiona Fraser, diretamente, por restringir os conflitos sociais a lutas organizadas e visíveis.

À la Michel de Certeau, embora sem retomá-lo, Honneth percebe as tramas de poder que geram opressão e resistência nas práticas concretas da vida cotidiana. Rompe, assim, a separação rígida entre a esfera pública e as arenas socialmente invisíveis. Para entender os processos sociais é preciso compreender o todo, percebendo que aquilo que se faz publica- 
mente articulado e manifesto é contextual e não encampa a totalidade do politicamente relevante.

Em terceiro lugar, a teoria do reconhecimento politiza emoções, que são frequentemente relegadas à esfera privada como elementos apolíticos ou, mesmo, despolitizantes. A política não é o espaço de puros interesses e cálculos racionais. Ela tampouco se faz por meio de uma argumentação fria. A política se faz com paixão, com indignação, com a contestação emotiva. Como Dewey, Honneth percebe a impulsão emocional que embasa processos mobilizatórios e lutas políticas. É Dewey (2010, p. 138) quem lembra que "não é possível separar entre si, em uma experiência vital, o prático, o intelectual e o afetivo e jogar as propriedades de uns contra as características dos outros". As emoções são parte constitutiva dos atos sociais.

Além disso, Honneth coloca o amor como uma das dimensões da justiça. A vivência dos afetos tem importância política e não pode ser negligenciada. O privado é político não apenas porque nele se conformam relações de dominação que sustentam assimetrias sociais. Na medida em que a construção dos selves é politicamente relevante, o afeto passa a ter papel fundamental, assegurando a edificação da autoconfiança que se articula ao autorrespeito e à autoestima. Obviamente, Honneth não está defendendo alguma comunidade idílica de amor irrestrito. A teoria do reconhecimento não é uma versão repaginada de um cristianismo afetuoso em que todos devem amar uns aos outros. Tanto que, em Honneth, o amor não é a base da solidariedade social. O afeto é político porque é uma dimensão fundamental para que os sujeitos possam se realizar. Assim, as condições de sua experiência devem ser alvo de reflexão e podem inspirar lutas políticas.

Como se nota, não há fronteiras rígidas entre o público e o privado na ideia de democracia apregoada por Honneth. Tal como na obra Dewey, o público é uma construção processual, refazendo-se o tempo todo. Contingente, ele se elabora no bojo das relações sociais a partir dos problemas a serem coletivamente enfrentados. Para a teoria do reconhecimento, tais problemas brotam ao longo dos processos identitários, atravessando diversas esferas sociais e dimensões da experiência.

\section{Uma visão não homogeneizadora de igualdade}

Democracia requer igualdade. Esta é constitutiva daquela, e não há como dissociá-las. No entanto, o sentido exato de igualdade varia enormemente 
nas teorias democráticas. Há concepções que restringem o princípio da igualdade a garantias formais de cidadania, e outras que defendem uma concepção mais ampla, em que a igualdade política depende de condições sociais e econômicas mais profundas. A essa altura do presente artigo, já deve estar clara a concepção ampliada de igualdade com que trabalha Honneth.

Resta, contudo, explorar outra dimensão do princípio de igualdade que embasa a teoria do reconhecimento. Essa dimensão encontra-se em profunda sintonia com as revisões da teoria democrática, feitas, sobretudo, pelos chamados teóricos da diferença. Estes salientam que a igualdade não pode implicar o apagamento das diferenças, porque elas são constitutivas das identidades. A crença simplista na igualdade humana também foi usada para sustentar desigualdades vigentes, seja porque impôs formas de vida a serem universalmente empregadas, seja porque não contemplou, em seu universalismo particularista, elementos importantes para a contestação de assimetrias.

Nesse sentido, nota-se a riqueza da noção de igualdade da teoria do reconhecimento. A igualdade só é justa enquanto permite a realização das singularidades. Justamente por isso, direitos universais e estima por idiossincrasias não se contradizem, como faz parecer Fraser (1997) com seu argumento sobre a esquizofrenia filosófica das lutas hodiernas. Igualdade e diferença não formam polos inconciliáveis, mas constituem-se mutuamente na realização de um ideal de justiça pautado pela autorrealização.

Nesse ponto, convém ressaltar, novamente, a proximidade da teoria do reconhecimento com a teoria democrática de Dewey. O pragmatista americano defende que a experiência efetiva da categoria geral "humana" depende do "desenvolvimento, por meio do toma-lá-dá-cá da comunicação, de um sentimento efetivo de ser um membro individualmente distinto de uma comunidade" (Dewey, 1954, p. 154). O sujeito é simultaneamente membro da comunidade e distinto dos demais. Honneth e Dewey admitem que as relações de trabalho têm papel relevante nesse processo, visto possibilitarem aos sujeitos contribuir, cada um a seu modo, para a construção da comunidade. Exatamente por isso, uma sociedade mais justa daria novos sentidos e configurações às relações de trabalho.

A singularidade humana não se restringe, contudo, à capacidade laboral dos sujeitos, e Honneth faz questão de destacar isso (cf. Hartmann e Honneth, 2006). Para ele, as pessoas podem contribuir de diferentes maneiras para a realização de objetivos sociais, lutando permanentemente por reconhecimento 
como seres humanos que são únicos. A singularidade é parte da universalidade do humano. Em termos arendtianos, poder-se-ia dizer que a pluralidade é inerente à condição humana.

As dimensões do reconhecimento propostas por Honneth (2003a) permitem vislumbrar, assim, um princípio não homogeneizador de igualdade. Se os direitos devem ser universais e valer para todos, é preciso que haja condições para que cada indivíduo possa realizar suas singularidades, desde que isso não implique a denegação do princípio da reciprocidade. As gramáticas morais formuladas ao longo das lutas por reconhecimento são igualitárias na medida em que não devem alimentar novas formas de opressão, possibilitando que a autorrealização se torne mais inclusiva e mais complexa.

Uma vez que a igualdade a que se visa não implica homogeneização, fica claro que a política envolve um permanente choque de singularidades. A competição e as lutas são constitutivas das ações dos sujeitos e do caminhar da sociedade. Não há uma harmonia a ser buscada ou um telos final conciliatório. A política se faz no choque, sem que este envolva a tentativa de destruição do outro. É aqui que a democracia se faz fundamental. Ela se torna o meio pelo qual tal jogo se efetiva para que a luta moral não se transforme em guerra.

\section{Liberalismo radical e comunitarismo?}

O quinto ponto forte de uma abordagem democrática orientada pela teoria do reconhecimento diz respeito à forma como esta se situa no panorama mais amplo da teoria política. A teoria do reconhecimento não é individualista nem comunitarista, no sentido como os termos são usualmente concebidos. Ela se constrói na interface entre essas abordagens, agregando pontos de um liberalismo complexo e radical a aspectos de um comunitarismo republicano não sectário. Nesse sentido, a teoria do reconhecimento coloca em xeque aspectos de uma dualidade canônica da teoria política, contestando sua validade heurística.

Por um lado, a abordagem de Honneth (2003a) coloca a autorrealização dos sujeitos no cerne da concepção de justiça. Honneth não é um autor da política da identidade coletiva que busca a valorização de grupos sociais. Ele tampouco coloca os valores coletivos à frente dos direitos e anseios individuais. $\mathrm{O}$ indivíduo, em sua singularidade, é central para sua obra. É esse sujeito que experiencia o desrespeito e articula lutas políticas, deslocando gramáticas morais da sociedade. O sujeito é agente. Ele é meio e fim do pro- 
cesso agonístico por meio do qual a justiça avança. As lutas por amor, por direitos e por estima podem ser travadas coletivamente, mas visam assegurar as condições de autorrealização individuais.

Por outro lado, esse indivíduo não se faz isoladamente, nem se autorrealiza de maneira atomística. Os sujeitos, seus anseios e as dimensões necessárias para sua realização se constroem socialmente. Os critérios para a avaliação da justiça e que guiam os processos identitários constroem-se intersubjetivamente nos quadros de contextos sócio-históricos. O indivíduo, em si, é fruto da sociedade em que se insere e dos fluxos interativos que o atravessam. Ademais, as lutas por reconhecimento só se tornam lutas sociais na medida em que a experiência de sofrimento se generaliza e se apresenta como uma demanda coletiva. $\mathrm{O}$ reconhecimento é uma empreitada intersubjetiva e, portanto, coletiva.

Essa complexa matriz conceitual torna difícil uma classificação simplista da obra de Honneth. Ele não é um liberal clássico, no sentido em que a própria teoria crítica questiona o conceito. Ele não defende uma abordagem individualista, nem vincula liberdade e igualdade a entidades predefinidas. No entanto, Honneth tampouco é um comunitarista que advoga a valorização de coletividades e a concessão de direitos grupais. Se fosse necessário defini-lo, Honneth estaria mais próximo dos enfoques centrados na interação, que rompem com a dicotomia indivíduo x coletividade.

Aqui, novamente, as semelhanças com a perspectiva de John Dewey chamam a atenção. É curioso que Dewey seja frequentemente percebido como um republicanista do início do século XX ou como um dos precursores do comunitarismo político (Pogrebinschi, 2004), embora tenha se dedicado vigorosamente à defesa de um liberalismo radical. Em "Liberalismo \& ação social" (1970 [1935]) e em "Liberdade e cultura" (1970 [1939]), ele tenta reconstruir a história do liberalismo, argumentando que era mal compreendido pelos críticos à direita e à esquerda. Para Dewey, era preciso romper com o individualismo e com a lógica do mercado para que o liberalismo pudesse se realizar em sua radicalidade, libertando os sujeitos e permitindo que se realizassem. As citações abaixo ilustram as rupturas por ele defendidas:

O fato de se haver utilizado, há mais de um século atrás, para justificar o autogoverno político, a teoria individualista e de ter ela ajudado a promoção de sua causa, não a faz agora, no presente, um guia digno de confiança da ação democrática (Dewey, 1970 [1939], p. 211). 
[A] causa do liberalismo se perderá se ele não se preparar para ir adiante, socializando as forças de produção, hoje disponíveis, de modo que a liberdade dos indivíduos resulte da própria estrutura da organização econômica (Dewey, 1970 [1935], p. 87).

Dewey evidencia que o individualismo é uma construção histórica, sem sustentação filosófica, já que a associação é constitutiva do ser. Seria preciso, assim, reinterpretar o lugar do indivíduo na teoria política: "Indivíduos ainda pensam, desejam e objetivam, mas o que eles pensam é consequência do comportamento deles sobre os outros e dos outros sobre eles" (Dewey, 1954, p. 24). Crenças, valores e intenções emergem da associação - associação essa que se torna reflexiva por meio da democracia, engendrando formas de cooperação, solidariedade e espírito de comunidade. Da comunidade cooperativa depende a realização individual.

Assim como em Honneth, nota-se, pois, uma abordagem que ultrapassa as categorias estanques, para construir uma visão interacional, que, a rigor, não é nem liberal, nem comunitarista. Essa complexidade traz elementos interessantes para se pensar a teoria democrática. A superação das desigualdades, que minam as condições da democracia, requer um foco na interação humana e na forma como os comportamentos recíprocos moldam sujeitos, coletividades e valores sociais. Se as assimetrias e estruturas sociais são reproduzidas nas interações humanas, elas também podem ser contestadas ao longo de tais interações. A contestação da opressão e a revelação de outros mundos possíveis emergem no bojo das relações sociais, que se configuram como um rico campo de investigação, para além do foco em indivíduos e grupos. A teoria do reconhecimento oferece, assim, os elementos para uma teoria democrática que se projeta para além da tradicional dicotomia entre liberalismo e comunitarismo.

\section{Considerações finais}

$\mathrm{O}$ presente artigo procurou argumentar que a teoria do reconhecimento oferece caminhos interessantes para a formulação de uma teoria democrática contemporânea centrada na discussão de desigualdades e opressões sociais. Para tanto, fez-se necessário, inicialmente, explorar a ideia de democracia tal como desenvolvida por John Dewey. Essa ideia possibilita pensar a democracia por uma ótica ampliada que ultrapassa a lógica restrita das instituições 
governamentais. Na sequência, buscou-se evidenciar a profunda relação entre alguns dos pilares da teoria do reconhecimento e o legado teórico do mencionado pragmatista.

Em seguida, a partir desse diálogo Honneth/Dewey, procurou-se advogar que a teoria do reconhecimento tem cinco pontos fortes para se pensar uma teoria democrática. Ela: (1) adota uma concepção não institucional de política; (2) parte da constatação da opressão; (3) ultrapassa a dualidade entre público e privado; (4) opera com uma visão não homogeneizadora de igualdade; e (5) quebra a cristalizada dicotomia entre liberalismo e comunitarismo. Com o desenvolvimento desses pontos, o artigo procurou mostrar que a teoria do reconhecimento permite pensar uma forma radical de democracia, para usar um conceito cujo uso vem se tornando mais frequente na literatura, embora ainda abrigue sentidos muito diversos.

É importante perceber que nenhum dos supramencionados pontos é exclusividade da teoria do reconhecimento. Ao contrário, apontamos, em alguns trechos, aspectos trabalhados por feministas, por democratas da diferença e por participacionistas. A questão é que o reconhecimento não apenas articula esses pontos mas o faz com base em uma teoria da justiça que se deseja crítica e emancipatória. Assim, independentemente de o reconhecimento ser classificado ou não como uma teoria democrática, defende-se a proficuidade de uma teoria democrática orientada pela noção de reconhecimento. Teoria essa que se mostra promissora para superar dualidades simplificadoras e visões restritivas, de modo que se pense a questão das desigualdades com a devida complexidade.

\section{Referências bibliográficas}

ALEXANDER, Jeffrey C. \& LARA, Maria Pia (1996). "Honneth's new critical theory of recognition”. New Left Review, n. 220, p. 126-136.

ANDERSON, Joel \& HONNETH, Axel (2005). "Autonomy, vulnerability, recognition, and justice”, em CHRISTMAN, John \& ANDERSON, Joel (eds.). Autonomy and the challenges to liberalism: new essays. New York: Cambridge University Press.

ARENDT, Hannah (2005). A condição humana. 10a ed. Rio de Janeiro: Forense.

DEWEY, John (1954). The public and its problems. Chicago: The Swallon. (1964). Teoria da vida moral. São Paulo: Ibrasa. 
(1970). Liberalismo, liberdade e cultura. São Paulo: Companhia Editora Nacional.

(2010). Arte como experiência. São Paulo: Martins Fontes.

FORST, Rainer (2007). "First things first: redistribution, recognition and justification”. European Journal of Political Theory, v. 6, n. 3, p. 291-304.

FRASER, Nancy (1997). "From distribution to recognition? Dilemmas of justice in a 'postsocialist' age", em Justice interruptus: critical reflections on the "postsocialist" condition. London: Routledge.

(2000). "Rethinking recognition". New Left Review, new series, n. 3, p. 107-120.

(2001). “Recognition without ethics?”. Theory, Culture \& Society, v. 18 , n. $2-3$, p. $21-42$.

(2003a). "Social justice in the age of identity politics: redistribution, recognition, and participation", em FRASER, Nancy \& HONNETH, Axel (eds.). Redistribution or recognition? A politicalphilosophical exchange. Londres, Nova York: Verso.

(2003b). "Distorted beyond all recognition: a rejoinder to Axel Honneth", em FRASER, Nancy \& HONNETH, Axel (eds.). Redistribution or recognition? A political-philosophical Exchange. Londres, Nova York: Verso.

HARTMANN, Martin \& HONNETH, Axel (2006). "Paradoxes of capitalism". Constellations, v. 13, n. 1, p. 41-58.

HONNETH, Axel (1997). "Review article: a society without humiliation?". European Journal of Philosophy, v. 5, n. 3, p. 306-324.

(2001a). "Recognition or redistribution? Changing perspectives on the moral order of society". Theory, Culture \& Society, v. 18, n. 2-3, p. 43-55.

(2001b) "Democracia como cooperação reflexiva: John Dewey e a teoria democrática hoje", em SOUZA, Jesse (org.). Democracia hoje: novos desafios para a teoria democrática contemporânea. Brasília: Editora UnB. (2003a). Luta por reconhecimento: a gramática moral dos conflitos sociais. São Paulo: 34 .

(2003b). "Redistribution as recognition: a response to Nancy Fraser", em FRASER, Nancy \& HONNETH, Axel (eds.). Redistribution or recognition? A political-philosophical Exchange. Londres, Nova York: Verso. (2003c). "The point of recognition: a rejoinder to the rejoinder", 
em FRASER, Nancy \& HONNETH, Axel (eds.). Redistribution or recognition? A political-philosophical exchange. Londres, Nova York: Verso. JOAS, Hans (1993). Pragmatism and social theory. Chicago, Londres: The University of Chicago Press.

MARKELL, Patchen (2003). Bound by recognition. Princeton: Princeton University Press.

MCBRIDE, Cillian (2009). "Demanding recognition: equality, respect, and esteem”. European Journal of Political Theory, v. 8, n. 1, p. 96-108.

MENDONÇA, Ricardo Fabrino (2009). "A dimensão intersubjetiva da auto-realização: em defesa da teoria do reconhecimento". Revista Brasileira de Ciências Sociais, v. 24, n. 70, p. 143-154.

(2011a). "Recognition and social esteem: a case study of the struggles of people affected by leprosy". Political Studies, v. 59, n. 4, p. $940-958$.

(2011b). "Contradictions of recognition: the struggles of people affected by leprosy in Brazil”. Trabalho apresentado no 61 ${ }^{\circ}$ Encontro Anual da Political Studies Association (PSA). Londres, 19 a 21 de abril. MENDONÇA, Ricardo Fabrino \& AYIRTMAN, Selen (2007). "Discourses of recognition in contemporary politics". Trabalho apresentado na conferência New Horizons in Political Philosophy, Australian National University. Canberra, 6 e 7 de dezembro.

OKIN, Susan M. (1989). Justice, gender, and the family. New York: Basic Books.

PATEMAN, Carole (1996). "Críticas feministas a la dicotomía público/ privado”, em CASTELLS, Carme (coord.). Perspectivas feministas en la teoría política. Barcelona: Paidós.

POGREBINSCHI, Thamy (2004). "A democracia do homem comum: resgatando a teoria política de John Dewey". Revista de Sociologia e Política, n. 23, p. 43-54.

(2005). Pragmatismo: teoria social e política. Rio de Janeiro: Relume Dumará.

SEGLOW, Jonathan (2009). "Rights, contribution, achievement and the world: some thoughts on Honneth's recognitive ideal". European Journal of Political Theory, v. 8 , n. 1, p. 61-75.

SMITH, Nicholas H. (2009). "Work and the struggle for recognition". European Journal of Political Theory, v. 8, n. 1, p. 46-60. 
THOMPSON, Simon (2006). The political theory of recognition: a critical introduction. Cambridge: Polity.

TULLY, James (2000). "Struggles over recognition and distribution". Constellations, v. 7, n. 4, p. 469-482.

(2004). "Recognition and dialogue: the emergence of a new field”. Critical Review of International Social and Political Philosophy, v. 7, n. 3, p. 84-106.

YOUNG, Iris Marion (2000). Inclusion and democracy. Oxford: Oxford University Press.

\section{Resumo:}

O presente artigo busca discutir as contribuições conceituais que surgem do diálogo entre a teoria do reconhecimento e a ideia de democracia, a fim de explorar o problema das desigualdades. O texto começa com uma apresentação da teoria do reconhecimento de Axel Honneth. Em seguida, desenvolvem-se algumas das principais ideias de Dewey, de modo a evidenciar as consequências delas sobre a teoria de Honneth. Desse frutífero diálogo, nasce uma abordagem democrática da justiça que tem, pelo menos, cinco pontos fortes: (1) adota uma concepção não institucional de política; (2) parte da constatação da opressão; (3) ultrapassa a dualidade entre público e privado; (4) opera com uma visão não homogeneizadora de igualdade; e (5) quebra a cristalizada dicotomia entre indivíduo e comunidade, que alimenta a suposta oposição entre liberalismo e comunitarismo.

Palavras-chave: reconhecimento; democracia; desigualdades; Honneth; Dewey

\section{Abstract:}

This article seeks to discuss the conceptual contributions that emerge from the dialogue between the theory of recognition and the idea of democracy, in order to explore the problem of inequalities. The article starts with a presentation of Axel Honneth's theory of recognition. Next, it develops some of the core ideas of John Dewey, showing their implications on Honneth's theory. From this fruitful dialogue, a democratic approach to justice comes out, and the paper argues that it has five main strengths: it adopts a noninstitutional concept of politics; (2) it starts with the observation of oppression; (3) it overcomes the duality between public and private; (4) it develops a non-homogenizing notion of equality; and (5) it breaks the crystallized dichotomy individual/community that pervades the often presumed opposition between liberalism and communitarism. Keywords: recognition; democracy; inequalities; Honneth; Dewey

Recebido em 11 de maio de 2012.

Aprovado em 20 de agosto de 2012. 